\title{
Potential Environmental Benefits of Ultralight Particleboards with Biobased Foam Cores
}

\author{
Christelle Ganne-Chédeville ${ }^{1}$ and Stefan Diederichs ${ }^{2}$ \\ ${ }^{1}$ Bern University of Applied Sciences, Institute for Materials and Wood Technology, Solothurnstrasse 102, 2500 Biel-Bienne, Switzerland \\ ${ }^{2}$ Thünen Institute of Wood Research, Leuschnerstr. 91c, 21031 Hamburg, Germany \\ Correspondence should be addressed to Christelle Ganne-Chédeville; gnc1@bfh.ch
}

Received 20 December 2014; Accepted 5 March 2015

Academic Editor: Nicole Stark

Copyright (C) 2015 C. Ganne-Chédeville and S. Diederichs. This is an open access article distributed under the Creative Commons Attribution License, which permits unrestricted use, distribution, and reproduction in any medium, provided the original work is properly cited.

\begin{abstract}
A new generation of ultralight particleboards (ULPB) with an expanded foam core layer produced in an in-line foaming step is under development. The environmental impacts of three types of ULPB containing foam based on 100\% polylactic acid (PLA), $100 \%$ expanded polystyrene, and 50\% PLA/50\% polymethyl methacrylate, as well as a conventional particleboard (PB), have been compared in an LCA. Two approaches were chosen for the assessment: first, the "EPD-approach" in accordance with EN 15804 for EPD of building materials and second, a holistic-approach which allows an expansion of the system boundaries in order to forecast the consequences of a broader replacement of PB with ULPB. The results show that most of the environmental impacts are related to raw materials and end-of-life stages. Both approaches show that the exchange of PB with ULPB with a foam core based on PLA leads to a reduction of greenhouse gas emissions. On the other hand, the PLA is responsible for higher ecotoxicity results in comparison to non-bio-based polymers mainly due to agricultural processes. Both approaches allowed the drafting of complementary advisories for environmental impact reduction addressed to the developers.
\end{abstract}

\section{Introduction}

Particleboards (PB) are pressed panels made out of wood particles and adhesives. They typically consist of a lower density core layer of coarse particles and high density surface layers made with finer particles. They typically have a density of $600-700 \mathrm{~kg} / \mathrm{m}^{3}$ and are used in very diverse applications like home and office furniture, cabinets, kitchens, flooring, load bearing applications in construction and diverse interior design elements. They show an improved homogeneity and stability in comparison to solid timber.

Initially, PBs were developed to valorize the large amount of particles produced in sawmills. Today, with the ambition of reducing production costs, the wood based panel industry aims to use less or cheaper materials and to reduce energy consumption while maintaining the properties in accordance with the relevant product standards.

The sandwich-like construction of PBs is advantageous for a high specific bending strength. To maintain this, developments started in the 1940s with the substitution of the core layer with honeycomb or similar hollow structure [1-3], and until today other strategies are being developed to reduce the density of the core layer: extrusion with hollow tubes, using low density wood species particles, or substituting the core layer with foam material in a sandwich construction. The latter strategy led to sandwich panels with a foam core made out of polyurethane or polystyrene which are established in the market today (density: $100-350 \mathrm{~kg} / \mathrm{m}^{3}$ ).

From a process perspective, these "ultralight" $\mathrm{PBs}$ (ULPB) can either be produced by producing the core layer and external layer separately and merging them in a separate pressing process, or by an in-line foaming step (patented by Luedtke et al. [4]) on continuous presses which are typically used in today's PB production.

Environmental impacts associated with conventional PBs arise mainly during the production of the adhesives, the combustion of fuel on site and the generation of electricity for the production steps at the panel manufacturers, whereby the particle preparation and finishing process take the leading positions [5-10]. But with regard to the complete life cycle 
of PBs and recognition that wood has a heating value of 15$20 \mathrm{MJ} / \mathrm{kg}$, the end-of-life processes may dictate the results depending on the assumptions made for the scenarios (i.e., incineration, landfilling, and thermal energy recovery).

ULPBs typically use less adhesive, fewer particles need to be prepared and dried, and as they are lighter, transport emissions may be reduced. On the other hand, the heating value per volume will be different from PBs and, depending on whether biobased or fossil-based foams are utilized, the supply chain of these materials and the end-of-life assumptions may be connected to impacts which differ greatly from those of PBs.

Hence, especially the end-of-life, the adapted continuous pressing process, the particle drying, the reduced supply of wood and adhesives, as well as the supply of foam materials needs to be the focus of LCA for ULPBs. Recognizing that wood used in PBs is typically a byproduct of the sawmill industry, LCA should also include the assessment of other routes for those byproducts. This surely includes the assessment of other routes if the foam material is based on byproducts.

A respective comparison of ULPBs (polyurethane foams) with PBs was conducted by Feifel et al. [11]. The authors concluded that the impacts were 2 to 3 times higher for the UPLBs. Unfortunately the results only consider cradle-togate effects and no inventory was published which would offer the possibility of a comparison to real ULPBs. A cradle-tograve assessment for ULPBs, substituting PBs, was further conducted by Feifel et al. [12] but focused only on honeycomb core layers and excluded the supply of wood.

From a resource perspective, an LCA conducted by Silva et al. [13] gives insight to results of PBs produced in Brazil, where $50 \%$ of the chips had been replaced with sugarcane bagasse. Results were compared to results from standard particle boards showing beneficial aspects in some impact categories and quite equal results in others. However, the endof-life was not considered in this study and the alternative byproduct routes of bagasse were not included. As Brazilian producers primarily use wood resources, no results could be derived for the alternative routes of sawmill byproducts typically used by European producers of PBs.

The primary target of the study is to analyze the environmental benefits or drawbacks of using ULPB with a foam core processed on a continuous press, for applications where conventional $\mathrm{PBs}$ are commonly used. In addition, as the described ULPBs are still in development, the secondary target is to identify the parameters with the largest influence on environmental impacts, helping the developers to understand which decision in design might lead to better or worse results in the overall environmental impact of the new product.

\section{Methodology}

2.1. Two-Pronged Strategy. Principally, LCA can be used for improvements by identification of key issues. Products can be benchmarked by comparing them to the LCA results of an average or another product. LCA can help to communicate environmental issues and on policy level the tool is used to supply strategic decision support.
In this context it is important to understand which question is addressed in the goal of the study. One would ask "what is?" to identify environmental key issues of the product life cycle or to benchmark one product against others. But to understand the consequences of a decision, the relevant question would be "what if?".

The two modelling approaches behind these questions are referred to as attributional (ALCA) and consequential life cycle assessment (CLCA) and their capabilities have been discussed extensively. It is generally understood that both approaches yield valuable insights [14-16] and some aspects are evident in one method and are overlooked in the other [17]. Therefore, this paper follows a two-pronged strategy.

2.2. The Harmonized Approach for Building Products. In Europe, the underlying LCA methodology for building products is defined in EN 15804 [18], which builds upon ISO 14044 [19] but clarifies open methodological choices where ISO 14044 [19] offers them. EN 15804 [18] defines the core product category rules for Environmental Product Declaration (EPD) built upon ISO 14025 [20].

In the context of this paper, the utilization of this methodology is intended to supply information on how the new products would compare to $\mathrm{PB}$, following the comparison principles of building products. It will be referred to in the text as the EPD-approach.

2.3. Expanding the Scope. The EPD-approach is based on an ALCA model. On the resource side it disregards the fact that the production of byproducts of a process is typically driven by the demand for the primary product and not for the byproducts. Hence the approach excludes the impacts of alternative routes for those byproducts. As the amount of these byproducts (wood or biobased foams) differs heavily between PB and ULPB, the EPD approach disregards a potentially crucial impact.

Further on, EN 15804 [18] and, respectively, its utilisation on building level, separate the benefits of the energy recovery at the end-of-life from the impact assessment. As this might be a reasonable approach at the building level, a direct comparison of products with different densities and heating values, which is the case for PB and ULPB, may be driven especially by those aspects of the product life cycle.

Therefore, the second approach in this paper includes aspects which are outside the system boundaries regarded in the EN 15804 [18], with the aim of including all processes and services which are likely to be affected by a replacement of $\mathrm{PB}$ with ULPB. This approach will be referred to in the text as holistic approach.

Both approaches will also give valuable insights for beneficial product development strategies.

2.4. Standards, Software and Databases. The LCA was done in accordance with the ISO 14040/14044 [19, 21], EN 15804 [18] and EN 16485 [22] standards using the Aveny LCA Software [23]. If not specified otherwise, the database Ecoinvent v2.2 was used for standard datasets [24]. 


\subsection{Description of the System under Study}

2.5.1. Manufacturing of Conventional PB (Cradle-to-Gate). The $\mathrm{PB}$ considered in this study is based on wood residues from sawmills, urea-formaldehyde (UF) resin as adhesive and produced in a continuous-press. Hydrochloric acid or liquid ammonia is used as hardener and paraffin is added for waterrepellence.

The production of $\mathrm{PB}$ begins with the preparation of the wood particles for the surface and core layers including chipping, classifying, screening, and drying. The particles are then blended with UF resin and hardener in a continuous flow mixer cooled with water. The mat is formed by deposition of the surface and core layer particles on a conveyer belt and goes to a roller press heated at $220^{\circ} \mathrm{C}$. After the pressing, the $\mathrm{PB}$ are sawn and cooled down by storage. The final density is $680 \mathrm{~kg} / \mathrm{m}^{3}$.

2.5.2. Forecasted Manufacturing of ULPB (Cradle-to-Gate). Based on the laboratory development we assume, that the ULPBs considered in this study are composed of surface layers made of wood particles, prepared in an identical manner as for the PB production, and a core layer of expanded polymers. Three ULPB core layer types are simulated in the study:

(1) A core layer made of EPS, which corresponds to the state of the art of the in-line foaming technology [25].

(2) A core layer made of a mix of PLA and polymethyl methacrylate (PMMA) (50/50\%), which corresponds to the current development formulation in the project [26].

(3) A core layer made of PLA (100\%) which corresponds to the aimed formulation.

EPS is directly available as granulate, preimpregnated with pentane as blowing agent. The mix of PLA and PMMA has to first be coextruded with a small quantity of talc in order to provide nucleation sites for the foaming and then it has to be granulated. Granulates of PLA or PLA/PMMA mix are then impregnated with liquid $\mathrm{CO}_{2}$ (blowing agent) in a batch reactor and stored for a short-time in a chiller at $10^{\circ} \mathrm{C}$ before they can be used in the production. The current ULPB laboratory developments allow the possible manufacturing process to be forecasted: the production of the considered ULPBs should be identical to the production of the PB, except for the mat forming and pressing phases. During the mat forming the technology stays the same as for PB but the coarse particles of the core layer are substituted by polymer granulate of EPS, PLA or the mix of PLA/PMMA preimpregnated with blowing agent. As the ULPB should have the same mechanical properties as the $\mathrm{PB}$, the bending stiffness is increased by surface layers of higher density. This means that the amount of surface layer particles in ULPB is increased in comparison to PB. Pressing occurs in 3 successive steps: surface layer compaction and consolidation step, expansion step and stabilization step (Figure 1). The first step occurs at a pressing temperature of $100^{\circ} \mathrm{C}$ whereas the last step (stabilisation) occurs at $20^{\circ} \mathrm{C}$ which implies the utilisation of a cooling system. After pressing, the last manufacturing steps of the ULPB are identical to those of the PB. The final density of the ULPB is $315 \mathrm{~kg} / \mathrm{m}^{3}$.

2.5.3. Use Phase and End-of-Life Scenario (Gate-to-Grave). A scenario was considered for the gate-to-grave part of the life cycle of the panel: the panels are transported to a furniture manufacturer where they are modified to be part of a piece of furniture (shelf) and then transported to the final user. During the use phase the furniture is stored in a house. At its endof-life it is picked up at the place of use by the municipal waste collection and burned in the municipal incineration plant.

2.6. Functional Unit. The functional unit is $1 \mathrm{~m}^{3}$ of panel (thickness $19 \mathrm{~mm}$ ), fulfilling the requirements of the EN 312 [27] and utilized as furniture shelf board. The different panel formulations are compared for the same life span. The units and quantities of the different raw materials used for the manufacturing of the functional unit are presented in Table 1. Because no detailed data was available on the internal waste flows of the production, all inputs of adhesives and additives were assumed to leave the manufacturer as content of the respective product analogous to Diederichs [28]. All products were regarded in the EPD-approach. The holistic approach only takes the PB and ULPB with a 100\% PLA core into account.

\subsection{System Boundaries}

2.7.1. EPD Approach. The EN 15804 [29] standard defines the categorization of life-cycle phases of building materials into stages from A (manufacturing) to C (disposal). Benefit or burdens out of the system boundaries can be presented as additional information in the $\mathrm{D}$ stage. The attribution of the life-cycle stages of the ULPB and PB following EN 15804 [29] is given in Figure 2.

All phases from cradle-to-grave are considered except the use phase of the product (shelf board in a furniture part), as it is considered equal for all products.

2.7.2. Holistic Approach. EPD and also the EN 15804 [29] are not specifically intended to declare the impact of the consequences of producing more of one product and less of another, but can be regarded as doing so, if the production of a unit of material or energy has the same environmental impact as producing an extra unit of it [30].

In other words, if a constraint in the market leads to the fact that an extra unit does not equal the average of all units produced so far, the EPD approach will not be able to answer the question: what would happen if a certain amount of conventional PB was replaced by ULPB with 100\% PLA core layer?

In the EPD approach, the supply chain of the corn used for PLA includes every flow, starting with the planting and fertilizing to the harvesting and transporting of the corn. But if more corn is produced to be used for the PLA, it requires more agricultural area, possibly replacing the production of other crops. If no additional corn is produced, but the corn available on the market is used, those processes which 
TABLE 1: Units and quantities of the raw materials used in the production of a $1 \mathrm{~m}^{3}$ panel. The bold data refer to functional units regarded in the holistic approach.

\begin{tabular}{|c|c|c|c|c|c|}
\hline Raw material input & Unit & $\mathrm{PB}$ & ULPB (EPS) & ULPB (PLA/PMMA) & ULPB (PLA) \\
\hline Residual wood & $\mathrm{m}^{3}$ & 1.38 & 0.59 & 0.59 & 0.59 \\
\hline PMMA & $\mathrm{kg}$ & - & - & 12.38 & - \\
\hline PLA & $\mathrm{kg}$ & - & - & 12.38 & 24.75 \\
\hline EPS & $\mathrm{kg}$ & - & 25.00 & - & - \\
\hline Hardener & $\mathrm{kg}$ & 2.00 & 0.94 & 0.94 & 0.94 \\
\hline UF & $\mathrm{kg}$ & 51.00 & 23.87 & 23.87 & 23.87 \\
\hline Talc & $\mathrm{kg}$ & - & 1.00 & 1.00 & 1.00 \\
\hline $\mathrm{CO}_{2}$ liquid & $\mathrm{kg}$ & - & - & 0.81 & 0.81 \\
\hline Organic additives & $\mathrm{kg}$ & 11.00 & 5.15 & 5.40 & 5.40 \\
\hline
\end{tabular}

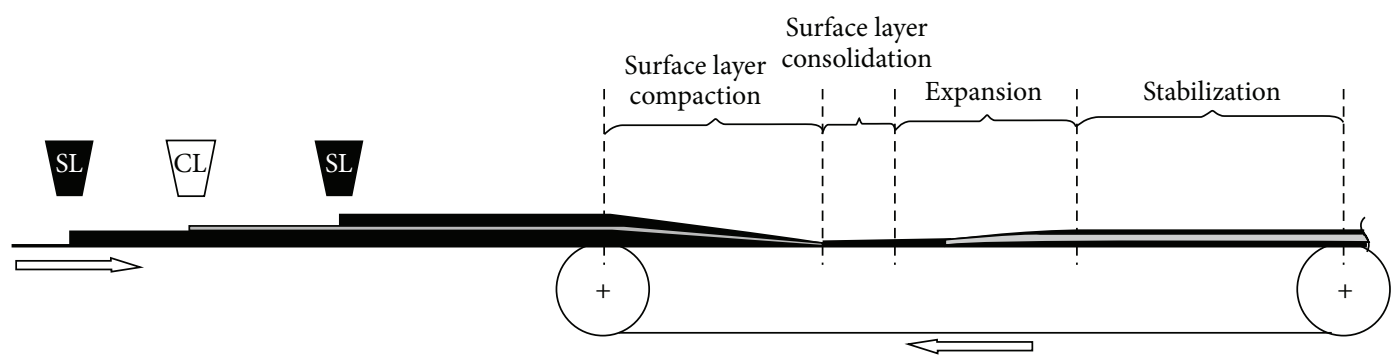

FIGURE 1: Description of the in-line foaming process for production of ultralight particle-board with a foam-core layer on a continuous press ( $\mathrm{SL}=$ surface layer; $\mathrm{CL}=$ core layer) (adaptation of Luedtke et al. [4]).

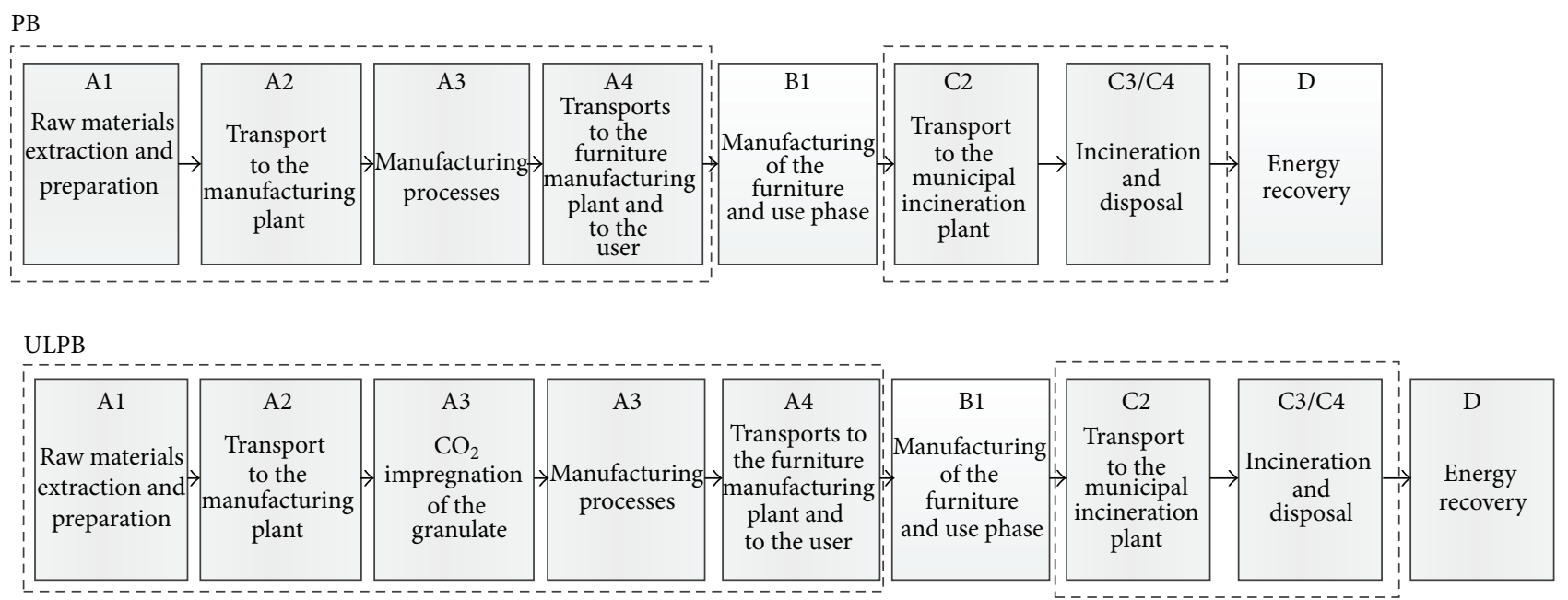

FIGURE 2: System boundaries following EN 15804 for the LCA of PB and all ULPBs.

would have used the corn instead need to switch to another feedstock.

In case of the wood residues used for the $\mathrm{PB}$, the model used in the EPD-approach includes all environmental impacts from the forest to the sawmill, whereas the impacts of the sawmill are allocated partially to the byproducts. This means, if the wood content of a panel is reduced, the LCA model reduces the impact from the sawmills as well. But the demand for sawmill byproducts does not necessarily lead to a reduced demand for the primary products of sawmills, which is sawn wood. Hence the same emissions arise from the sawmill industry and the same amount of byproducts are available on the market. But instead of the panel producers, probably others will use the byproducts.

The EPD-approach neglects the market constraints especially with regard to these two aspects. Other inputs and outputs of the PB and ULPB production with high impact, energy demand, or mass are the supply of electricity and the glue which is primarily made of the base chemicals formaldehyde and urea. Since these substances are mainly derived 
Conventional PB production

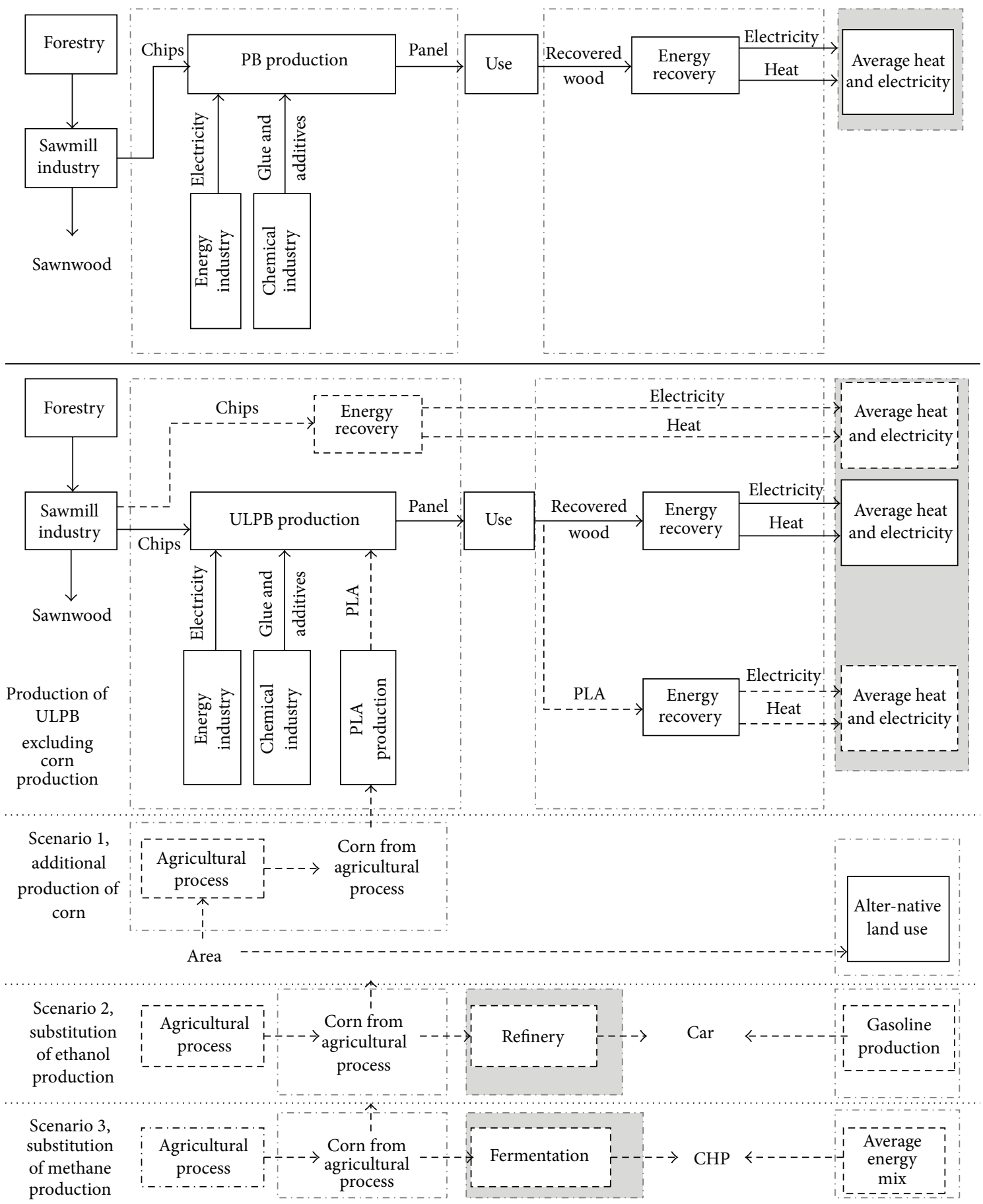

FIGURE 3: System boundaries of the holistic approach. Dashed processes and lines represent the affected processes of an increased production of ULPB (100\% PLA core).

from nonrenewable resources and are not typical byproducts of other processes, market constraints are assumed to be negligible.

Figure 3 shows the model which underlies the holistic approach. On the top, the production of the conventional PB is shown. It is the same model as used for the EPD approach including transports to the user and also to the disposal but it excludes the sawmill supply chain and includes the energy recovery at the end-of-Life. The grey system boundaries describe a system expansion. In the case of $\mathrm{PB}$, the energy generated during disposal is assumed to replace energy from the average generation processes of heat and electricity. Hence the impact has to be subtracted from the model.

Just below, the production of the ULPB with 100\% PLA is shown without the production of the corn for PLA. The dashed lines mark all flows and processes which need to be 
added or changed if the $\mathrm{PB}$ production is replaced by the production of the ULPB.

The production of sawmill byproducts is independent from the change in production within the panel industry. Therefore, the chips which were used for the core layer and those which were used to generate the energy for drying the core layer are assumed to be burned directly without being used for material purposes. The PLA core is burned in context with the disposal of the panel; energy is recovered (system expansion, grey field). The process of producing PLA from corn is included but (initially) without the corn.

Some processes used for $\mathrm{PB}$ production are also used for ULPB production, but the flow quantity changed: less electricity, glue, and additives are needed.

As it is not clear if additional corn is produced or if not which feedstock is replaced, three scenarios for the corn production/displacement are analysed:

(i) Scenario 1 (S1) describes the impact if additional corn has to be grown, including impacts of agricultural processes and the impact of land use change triggered by this extra production.

(ii) Scenario 2 (S2) describes the impact if available corn is used for PLA which would have been used for the production of bioethanol to replace gasoline. This is a relevant question for the US, where bioethanol is produced from corn.

(iii) Scenario 3 (S3) describes a typical German case. Available corn which would have been used for the production of biogas (methane) is used for PLA instead. Hence the energy derived from the methane (biogas) has to be substituted.

2.8. Inventory. Data for the production of $1 \mathrm{~m}^{3}$ of conventional PB $\left(680 \mathrm{~kg} / \mathrm{m}^{3}\right)$ from cradle-to-gate correspond to the Ecoinvent v2.2 process "Particleboard Indoor use" [8].

Data regarding the formulation of the ULPB arise from the last available laboratory developments of the NRP 66 project. In order to forecast the situation of an industrial production, the inventory was based on the available dataset from Ecoinvent for LCA of particleboard production [8]. The first step was to disaggregate the energy consumption of the manufacturing step of the Ecoinvent dataset following the proportions given in the literature [10] in order to spread it into single manufacturing stages (Table 2). As the stage "mat forming" is not described in the publication of Frühwald et al. [10], this data is based on assumptions made by the authors. The repartition of the total gas consumption of the Ecoinvent data between the stages Drying and Others is also an assumption.

Based on the laboratory data, the ratio between the amount of wood used in PB and used in ULPB is 0.422 . This ratio was applied to calculate the ULPB flows linked to wood flows (wood transport to the plant, electricity for particle preparation, waste water treatment from particle preparation, drying thermal and electrical energy, VOC and particulate emissions during drying, and wood chips volume as byproduct). Also based on laboratory data, the ratio between the amount of UF glue used in $\mathrm{PB}$ and used in ULPB is 0.468 . This ratio was applied to calculate the flows of ULPB linked to the glue flows (Hardener, Transport glue and additives to the plant, electricity and cooling water for gluing, and formaldehyde emissions). The gate-to-gate inventories (Modules A3) based on the functional unit of the four types of panels is presented in Table 4. Flows which are already included in Table 1 are not listed here. Further detailed data sources used and assumptions made for the Life Cycle Inventory of PB and ULPB from cradle-to-grave are in Appendix 1 in Supplementary Material available online at http://dx.doi.org/10.1155/2015/383279.

Some additional data and assumptions were necessary for the holistic approach (Table 3). The agricultural process to produce the corn is based on data from Searchinger et al. [31] and PE International [32]. The land use change effects are modelled according to results summarized by Wicke et al. [33]. These refer to land use change models based on market equilibrium models which consider effects called "indirect land use changes," including land use change in one geographical context which triggers land use elsewhere to continue to meet demands and also the change of crop prices, which results in more land taken elsewhere for the production.

Data for corn-to-wheel production are taken from Searchinger et al. [31] in combination with conversion factors from Shapouri et al. [34]. Gasoline production and combustion emissions are derived from PE International [32]. Emissions for the fermentation from corn to the methane and utilization in a CHP plant are taken from Vogt [35] for a $500 \mathrm{kWel}$ plant. Supply of electricity and heat is derived from PE International [32].

2.9. Impact Categories. For an EPD following the standard EN 15804 [29], three categories (environment, resources, and wastes) of indicators are disseminated. In this study we show only the EN 15804 [29] environment category indicators following CLM2001 [36]: Global Warming Potential 100 years with biogenic carbon accounting following EN 16485 (GWP), Global Warming Potential without biogenic carbon $\left(G_{W P}^{*}\right)$, Ozone Depletion Potential steady state (ODP), Acidification Potential (AP), Eutrophication Potential (EP), Photochemical Ozone Creation Potential (POCP); Abiotic Depletion Potential Elements (ADPE), Abiotic Depletion Potential Fossil (ADPF). We also present the results of two additional multi-criteria Life Cycle Impact Assessment (LCIA) methods of interest in Switzerland: Ecological Scarcity 2006 [37] expressed in Eco-factors-in German: Umweltbelastungspunkte (UBP) and USETox fate and freshwater ecotoxicity [38], expressed in Comparative Toxic Unit ecotoxicity (CTUe). For the holistic approach only GWP* will be reported.

2.10. Sensitivity Analysis. A sensitivity analysis was carried out for the EPD approach in order to evaluate the uncertainties of the LCIA results. The parameters, which were identified as relevant or uncertain (because of assumptions), were perturbed marginally in order to observe their effect on the final result. The effect of $10 \%$ decrease of several relevant 
TABLE 2: Disaggregation of the energy consumption for each manufacturing stage (A3 modules) of a $1 \mathrm{~m}^{3}$ conventional PB (Ecoinvent v2.2 dataset) using literature information and assumptions.

\begin{tabular}{|c|c|c|c|c|c|c|c|}
\hline Manufacturing stage & Particle preparation & Drying & Gluing & Mat forming & Pressing & Others & Total \\
\hline Electricity (\%) & 31 & 21 & 5 & 4 & 21 & 18 & 100 \\
\hline Electricity $\left(\mathrm{kWh} / \mathrm{m}^{3}\right)$ & 32 & 22 & 5 & 4 & 22 & 19 & 104 \\
\hline Electricity $\left(\mathrm{MJ} / \mathrm{m}^{3}\right)$ & 116 & 79 & 19 & 15 & 79 & 67 & 374 \\
\hline Wood (\%) & & 83 & & & 17 & & 100 \\
\hline Wood $\left(\mathrm{MJ} / \mathrm{m}^{3}\right)$ & & 913 & & & 187 & & 1,100 \\
\hline Fossil (\%) & & 41 & & & 13 & 46 & 100 \\
\hline Heavy oil $\left(\mathrm{MJ} / \mathrm{m}^{3}\right)$ & & 17 & & & 21 & 48 & 86 \\
\hline Light oil (MJ/m³) & & 17 & & & 21 & 48 & 86 \\
\hline Natural gas $\left(\mathrm{MJ} / \mathrm{m}^{3}\right)$ & & 100 & & & & 54 & 154 \\
\hline Total fossil (MJ/m³) & & 134 & & & & 150 & 326 \\
\hline Total energy $\left(\mathrm{MJ} / \mathrm{m}^{3}\right)$ & 116 & 1,125 & 19 & 15 & 266 & 217 & 1758 \\
\hline Total energy (\%) & 7 & 64 & 1 & 1 & 15 & 12 & 100 \\
\hline Total energy $\left(\mathrm{kWh} / \mathrm{m}^{3}\right)$ & 32 & 313 & 5 & 4 & 74 & 60 & 488 \\
\hline
\end{tabular}

TABLE 3: $\mathrm{CO}_{2}$ emissions from the additional processes of the model. Ranges are analyzed in terms of their impact on the totals.

\begin{tabular}{lc}
\hline Process & $\mathrm{kg} \mathrm{CO}_{2}$-eq $/ \mathrm{kg}$ corn \\
\hline Agricultural process & $0.19-0.61$ \\
Alternative land use & $0.05-0.86$ \\
Refinery (corn-to-wheel) & $0.38-0.40$ \\
Gasoline production (cradle to wheel) & 0.75 \\
Fermentation (corn to CHP) & $0.03-0.30$ \\
Supply of electricity and heat & $0.18-0.31$ \\
\hline
\end{tabular}

resources (wood and fossil fuels), energy consumption during manufacturing (electricity and heat), transport distances (A2, A4, and C2 modules), and the density of the panels as well as the effect of the substitution of $10 \%$ PMMA with PLA in the ULPB with PLA/PMMA core were calculated for the impact category GWP* and Ecological Scarcity 2006.

For the holistic approach the maximum and minimum values of the additional data and assumptions were included in the scenarios. Therefore minimum and maximum results exist for each scenario.

For land use change calculations, maximum values are based on Searchinger at al. [31], and minimum values are based on Laborde [39]. Three scenarios on methane leakages [35] were applied for the fermentation from corn to methane, and different carbon intensities were used for electricity generation in the model (Table 3).

\section{Results}

\subsection{EPD Approach}

3.1.1. Comparing Life Cycle Stages. The relative impacts of the different ULPB life cycle stages for each indicator are presented in Figure 4. Detailed results are available in Appendix 2. For all indicators considered, except the Ecological Scarcity, the raw materials stage (A1 module) has the highest impacts.
Thereafter the disposal ( $\mathrm{C} 4$ module) followed by the manufacturing processes (A3 processes) are relevant. Considering that the disposal is mainly influenced by the quantity of material to be disposed of, both stages Al and C4 will have the tendency to progress proportionally (reducing the amount of raw material will reduce the environmental impact due to the disposal). But the core layer composition could affect this proportionality. Ecological Scarcity results heavily weigh on the environmental effects of the disposal. The transport stages (A2, A4, and C2) have the lowest environmental impact for all considered indicators.

3.1.2. Raw Materials. As the raw material stage (A1 module) seems to be the most critical stage, the GWP* of this stage was analysed first. The obtained results show that the polymer composition of the core layer influences the global result of GWP* . The PMMA, which is used at the moment in the formulation in order to enhance the foaming process, represents $41 \%$ of the GWP* of the Module A1. The production of PMMA requires several intermediate products [40], all derive from fossil resources (crude oil and natural gas), which explains this high GWP* score. The UF resin (32\% of the GWP* of Module A1) is also a problematic raw material because of the intensive fossil resources use for manufacturing. As has already been observed by other authors, UF resin has the greatest impact in $\mathrm{GWP}^{*}$ of $\mathrm{PB}$ $[5,6,9]$. Finally the PLA, representing $18 \%$ of the Module A1 GWP* score, needs an important amount of fossil energy for production and agricultural processes even if produced from renewable resources. Detailed scores for Ecological Scarcity show that PLA, PMMA, and UF represent 29\%, 30\%, and $27 \%$, respectively, of the A1 module. In this model the emissions to air $\left(\mathrm{CO}_{2}\right.$ emissions of fossil fuels for energy purpose) and to water (emissions of nitrate and phosphorus from fertilizers for corn grown as PLA raw material) during manufacturing of the polymers are predominant impacts. When looking at the ecotoxicity results using USETox PLA represent $45 \%$, UF $32 \%$, and PMMA $12 \%$ of the A1 module. Biocides (mostly atrazine and chlorpyrifos) used for the corn 
TABLE 4: Detail inventory for $1 \mathrm{~m}^{3}$ panel from gate-to-gate (Module A3).

\begin{tabular}{|c|c|c|c|c|c|}
\hline Flow & Unit & $\mathrm{PB}$ & ULPB (EPS) & ULPB (PLA/PMMA) & ULPB (PLA) \\
\hline \multicolumn{6}{|c|}{ Input } \\
\hline \multicolumn{6}{|l|}{ Resources } \\
\hline Water for cooling & $\mathrm{m}^{3}$ & 0.30 & 0.14 & 0.14 & 0.14 \\
\hline \multicolumn{6}{|l|}{ Equipment } \\
\hline Plant & Count & $3.33 E-08$ & $3.33 E-08$ & $3.33 E-08$ & $3.33 E-08$ \\
\hline Batch reactor & Count & & & $3.33 E-08$ & $3.33 E-08$ \\
\hline Absorption chiller & Count & & & $5.88 E-06$ & $5.88 E-06$ \\
\hline Liquid storage tank & Count & & & $1.31 E-09$ & $1.31 E-09$ \\
\hline \multicolumn{6}{|l|}{ Energy } \\
\hline Electricity & $\mathrm{kWh}$ & 104.00 & 69.98 & 72.00 & 72.00 \\
\hline Heat & MJ & 1426.00 & 821.05 & 821.05 & 821.05 \\
\hline ...thereof Biomass & MJ & 1100.00 & 572.29 & 572.29 & 572.29 \\
\hline ...thereof Gas & MJ & 154.00 & 96.22 & 96.22 & 96.22 \\
\hline ...thereof Oil & MJ & 172.00 & 152.54 & 152.54 & 152.54 \\
\hline \multicolumn{6}{|c|}{ Output } \\
\hline Product & $\mathrm{m}^{3}$ & 1 & 1 & 1 & 1 \\
\hline Byproducts: wood chips & $\mathrm{m}^{3}$ & 0.35 & 0.15 & 0.15 & 0.15 \\
\hline Waste water & $\mathrm{m}^{3}$ & 0.04 & 0.02 & 0.02 & 0.02 \\
\hline Heat & MJ & 375.00 & 158.25 & 158.25 & 158.25 \\
\hline \multicolumn{6}{|l|}{ Emissions } \\
\hline $\mathrm{CO}_{2}$ fossil & $\mathrm{kg}$ & 22.34 & 17.54 & 18.35 & 18.35 \\
\hline $\mathrm{CO}_{2}$ biogenic & $\mathrm{kg}$ & 106.37 & 55.34 & 55.34 & 55.34 \\
\hline $\mathrm{NO}_{x}$ & $\mathrm{~kg}$ & 0.13 & 0.07 & 0.07 & 0.07 \\
\hline $\mathrm{SO}_{x}$ & $\mathrm{~kg}$ & 0.04 & 0.04 & 0.04 & 0.04 \\
\hline NMVOC & $\mathrm{kg}$ & 0.17 & 0.07 & 0.07 & 0.07 \\
\hline Particulates & $\mathrm{kg}$ & 0.08 & 0.03 & 0.03 & 0.03 \\
\hline Formaldehyde & $\mathrm{kg}$ & $3.00 E-03$ & $1.40 E-03$ & $1.40 E-03$ & $1.40 E-03$ \\
\hline Pentane & $\mathrm{kg}$ & & 2.00 & & \\
\hline
\end{tabular}

agricultural production are mostly responsible for high soil emissions of the PLA in USETox. Metal emissions to air (vanadium and nickel) and to water (chromium) during the manufacturing stages of UF and PMMA explain the score of these polymers in USETox.

3.1.3. Manufacturing Process. The manufacturing steps with high GWP* impacts are the finishing (due to high electricity demand for sanding and sawing, etc.), the pressing, and drying (due to electricity and heat from fossil fuels), and the particle preparation (due to high electricity demand for particle sieving and screening) (Figure 5). The high GWP* observed for all processes involving electricity point out that the type of the electricity mix used in the plant might be a relevant factor influencing the results of the A3 modules. For the Ecological Scarcity the drying stage has the highest score, due to the emissions of particulates. Pressing, finishing and particle preparation stages are, likewise for GWP*, relevant stages in this model due to the consumption of electricity. USETox results of the manufacturing stages are in the same order of relevance than $\mathrm{GWP}^{*}$ results mainly due to the emissions to air produced during the combustion of fossil fuels and the generation of the consumed electricity.
3.1.4. Transport. Environmental impacts due to transports are related to the means of transportation used, the distance driven and the weight of the material transported. Based on the chosen scenario the transport to the user (A4 module) has the highest impact, because it is the less optimized transport (a small quantity of panel on a relatively long distance).

3.1.5. Disposal. In the incineration process all polymer based on fossil resources (UF, PMMA, and paraffin) release fossil $\mathrm{CO}_{2}$, which is directly accounted in the GWP* score. Biobased materials (wood and PLA) have less influence on the GWP* score of the incineration module. Considering the Ecological Scarcity method, the emissions into air (dioxins) and water (total organic carbon) during incineration of wood are highly weighted. The compounds manufactured from fossil fuels contribute to a lesser extent to the score, mainly due to their fossil $\mathrm{CO}_{2}$ emissions. Finally in USETox, the disposal of UF has the highest score in the incineration (about $60 \%$ of the C4 module CTUe) due to emissions into water (heavy metals).

3.1.6. Effect of Production Capacity Reduction on GWP. Lüdtke [41] showed that an in-line foaming process needs a reduction 


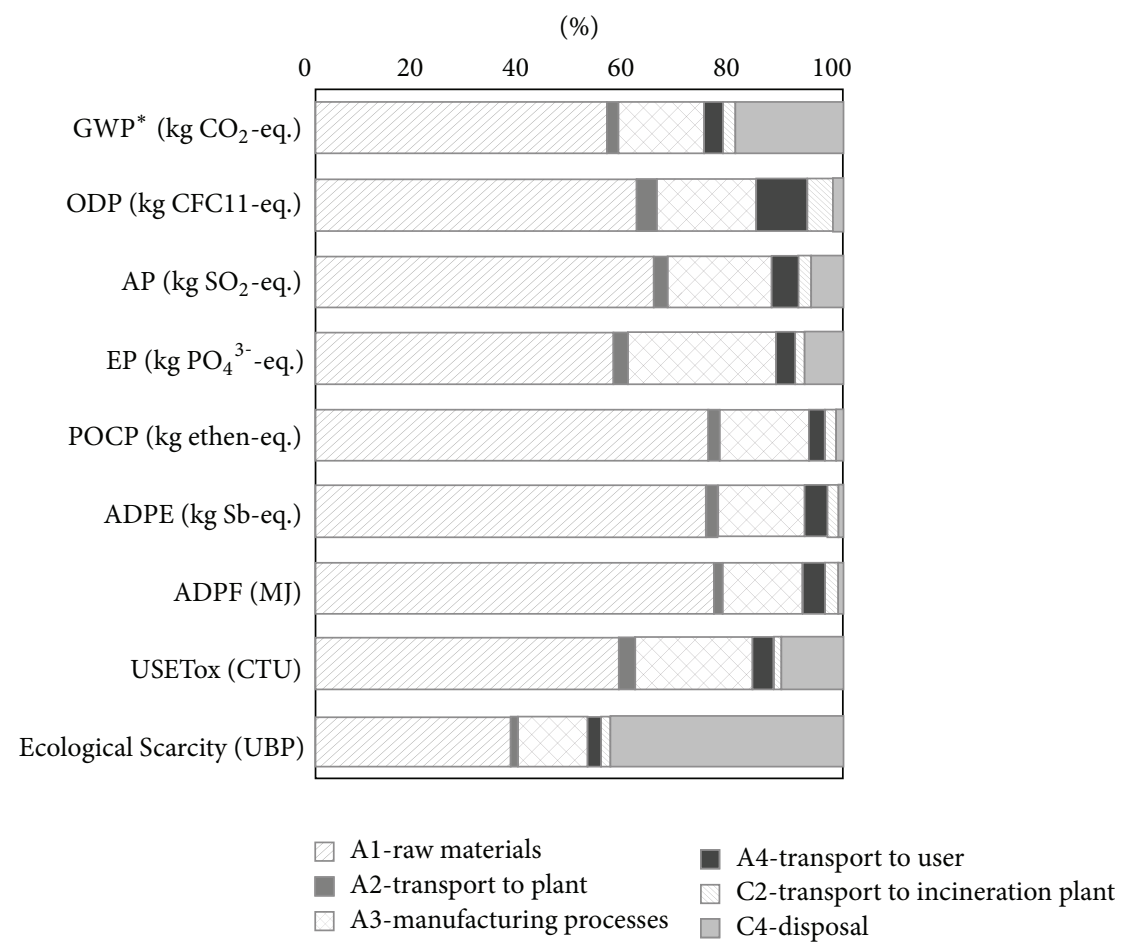

FIGURE 4: Relative environmental impact assessment of the ULPB for each life cycle stage corresponding to EN 15804 modules for the 9 indicators considered.

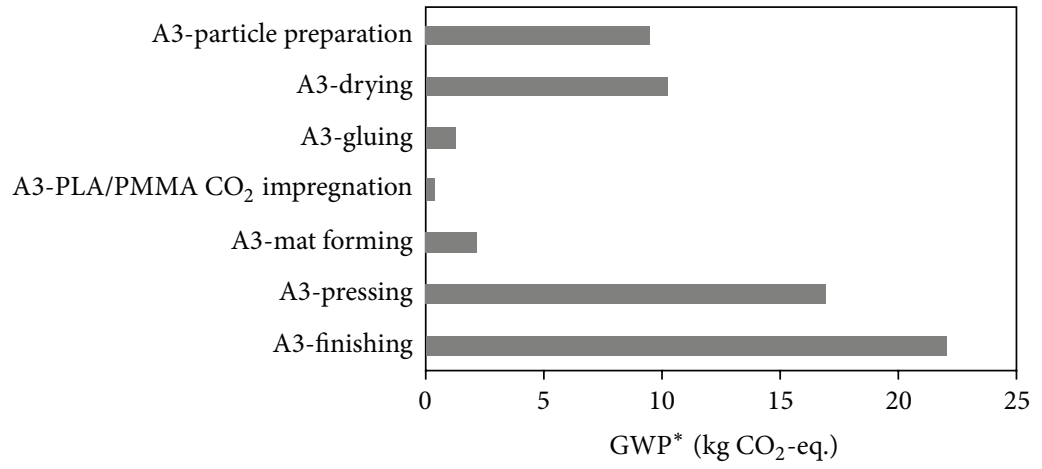

FIGURE 5: GWP* of all manufacturing stages (A3 modules) for the ULPB with PLA/PMMA core.

of the speed of production. Indeed the foam needs to be expanded and the panel has to cool down before it can be cut or sanded. This could represent a decrease of the production capacity of about $50 \%$. The effect of the reduction of speed on the GWP* of accumulated process $\mathrm{Al}$ to $\mathrm{C} 4$ has been simulated. The results of the calculation show that a decrease of the production capacity from $600000 \mathrm{~m}^{3} / \mathrm{yr}$ to $300000 \mathrm{~m}^{3} / \mathrm{yr}$ would increase the GWP* of the overall ULPB LCA of $15 \%$.

3.1.7. Effect of Core Layer Substitution. The impacts of the four core layer cases for the GWP*, Ecological Scarcity, and USETox are presented in Figures 6, 7, and 8. For both GWP $^{*}$ and the Ecological Scarcity method, the cumulative impacts of the Stages Al to C4 are higher for the wood core layer than all other ULPB cores simulated. This is, for the GWP*, mainly due to a higher amount of particles to prepare in the manufacturing process as well as the increase of transport emission due to the higher density of the panel. For the ecological Scarcity, the wood core shows a significant drawback due to process-specific burdens of the incineration (see Section 3.1.5).

Regarding the different ULPB core types, the core containing PMMA shows the highest impact for the GWP* and the Ecological Scarcity methods. This is mainly due to the high fossil energy consumption during manufacturing of PMMA. The substitution of PMMA with PLA shows benefits in the GWP ${ }^{*}$ and the Ecological Scarcity method. Concerning GWP*, the substitution of $1 \mathrm{~kg}$ PMMA with PLA will allow a decrease of $6 \mathrm{~kg} \mathrm{CO}$-eq. for Stages A1 to C4. 


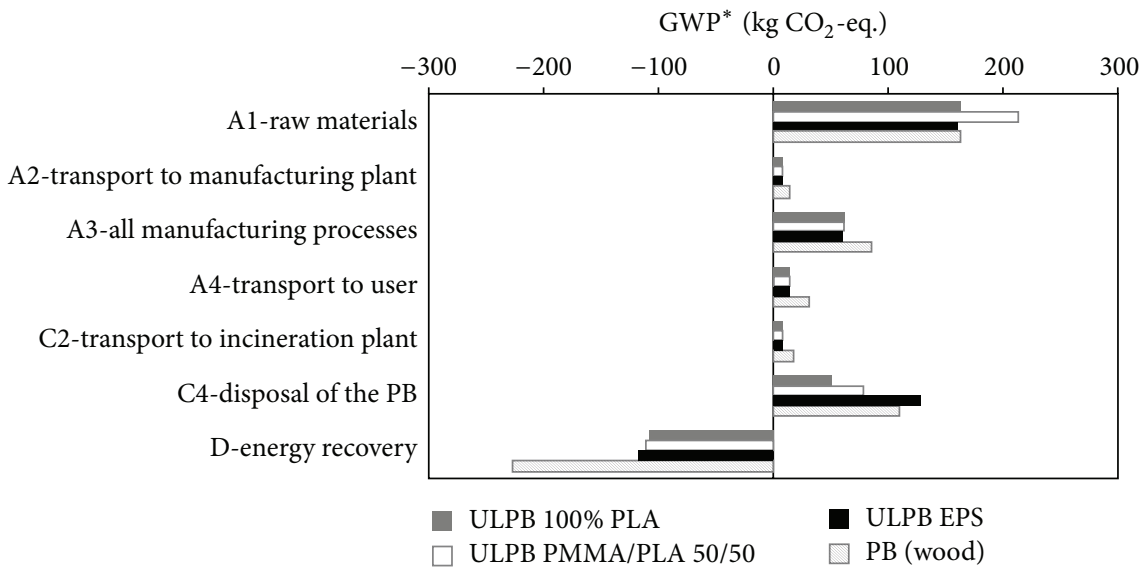

FIGURE 6: LCA impact category GWP* results of $1 \mathrm{~m}^{3}$ panel with different core layer compositions.

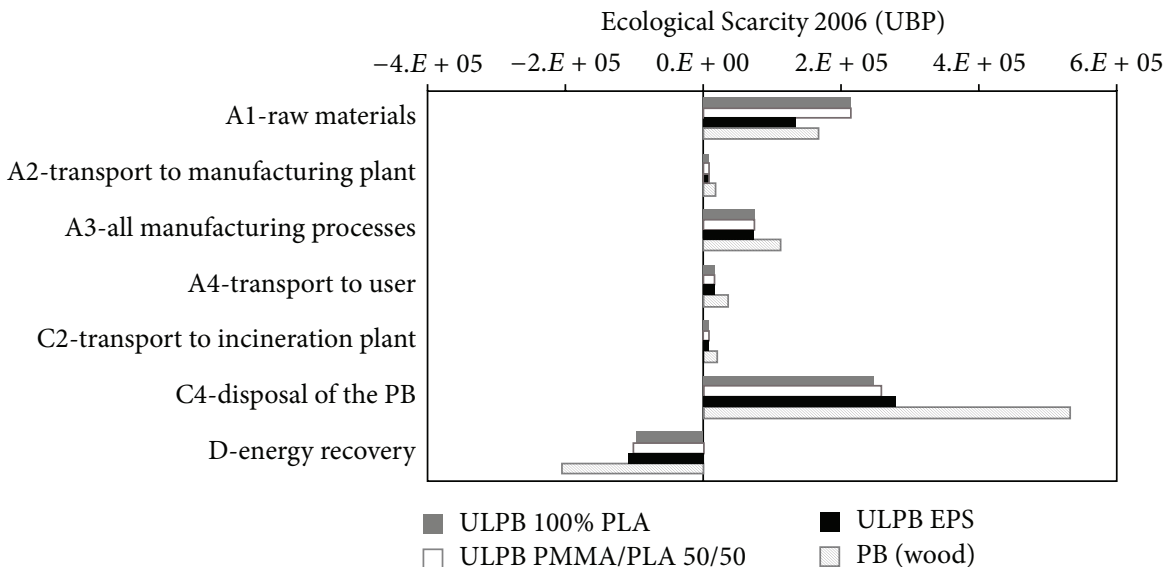

FIGURE 7: LCA impact category Ecological Scarcity results of $1 \mathrm{~m}^{3}$ panel with different core layer compositions.

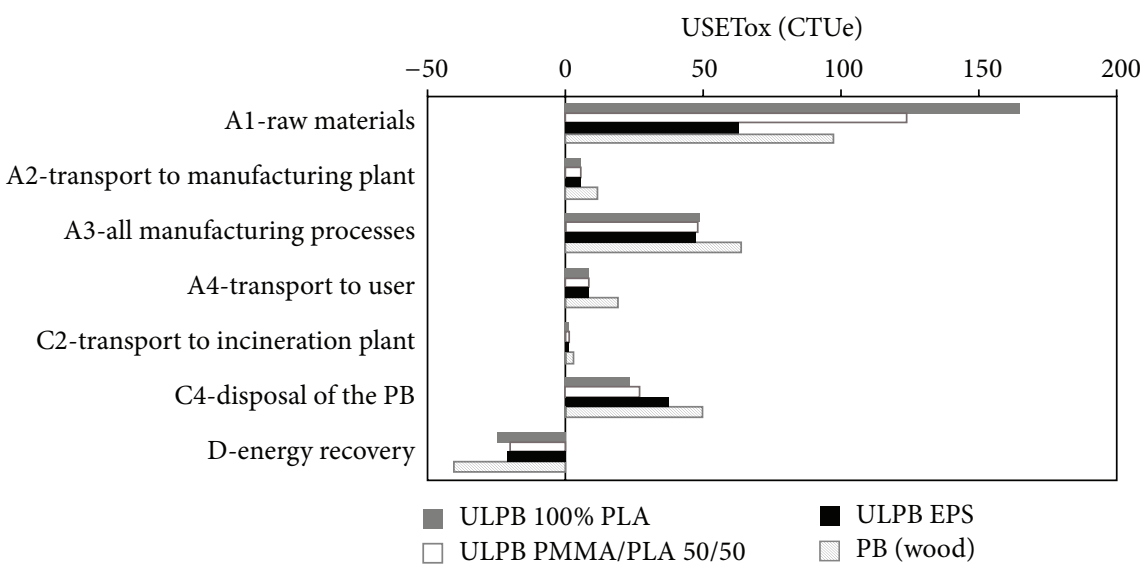

FIGURE 8: LCA impact category USETox results of $1 \mathrm{~m}^{3}$ panel with different core layer compositions.

EPS causes slightly more fossil $\mathrm{CO}_{2}$ than PMMA during stage $\mathrm{C} 4$ due to the higher carbon content of this polymer. Core layers containing PLA have a higher influence for the stage A1 on the ecological Scarcity method. Analogously, the USETox results show that the panel containing PLA has a considerable drawback on the ecotoxicity, mainly in Module A1. Reasons are the same as explained in Section 3.1.2. PMMA is also problematic in terms of USETox as the manufacturing of this polymer causes relevant emissions to water (see Section 3.1.2). The ULPB with EPS foam core has less ecotoxic 
effect in Module A1 than the $\mathrm{PB}$, this is directly linked to the reduced amount of UF.

3.1.8. Sensitivity Analysis. The results are very sensitive to the density of the panels ( $10 \%$ change leads to $7.5 \%-9.2 \%$ impact change). It has a direct influence on the raw material module (A1), on the transport modules (A2, A4, and C2), on the disposal module (C4), and on some of the manufacturing processes (A3 modules), especially the particle preparation process. This confirms that the amount of raw material used has a high significance on the model. The reduction of $10 \%$ PMMA (replaced by $10 \%$ PLA) in the core layer had a moderate effect on the models GWP* $(-2.2 \%)$ and USETox (1.7\%) whereas it has a nonsignificant effect on Ecological Scarcity $(-0.3 \%)$. The scenario of $10 \%$ reduction of electricity consumption, heat production, and fossil fuels in heat generation mix in production processes allow us to evaluate the uncertainties due to the assumption made on the energy flows during production of the panels. For all three impact categories observed, the perturbations did not significantly change the overall results (less than $1.3 \%$ of the original scenario). This means that the assumption made for these processes (A3 modules) does not influence the model to a relevant extent. Calculated scenarios for $10 \%$ reduction of transport distances of the main components and products are also not perturbing the system noticeably (less than 1.2\%). This confirms the low contribution of transport processes to the entire system.

3.2. Holistic Approach. Figure 9 shows the results of the holistic approach. The first (white) beam on the left shows the total difference between the conventional $P B$ production and the production of ULPB excluding corn production as defined in Figure 3 ( $86.8 \mathrm{~kg} \mathrm{CO}$-eq. per $\mathrm{m}^{3}$ of panel). To complete the calculation, the three scenarios are added to the beam with their minimum and maximum values. If it is assumed that extra corn has to be produced (Scenario 1), the maximum impact of the extra corn production, including indirect land use change, is $55 \mathrm{~kg} \mathrm{CO}$-eq. per $\mathrm{m}^{3}$ of panel, leaving a remaining benefit of $32 \mathrm{~kg} \mathrm{CO}_{2}$-eq. per $\mathrm{m}^{3}$ of panel for the ULPB.

If available corn is used for the production of PLA and the bioethanol which would have been produced from that corn needs to be replaced by conventional gasoline (Scenario 2), the remaining benefit will be between 73 and $74 \mathrm{~kg} \mathrm{CO}_{2}$-eq. per $\mathrm{m}^{3}$ of panel. If corn is used which would have been used in a biogas fermentation process (Scenario 3), the remaining benefit will be at least $76 \mathrm{~kg} \mathrm{CO}_{2}$-eq. per $\mathrm{m}^{3}$ of panel. In the case of high methane leaks in the fermentation process, the benefit is even $91 \mathrm{~kg} \mathrm{CO}_{2}$-eq. per $\mathrm{m}^{3}$ of panel.

\section{Discussion}

4.1. The Global Warming Potential. The two approaches produce similar results, which lead to the same conclusion in terms of greenhouse gas reduction potentials by exchanging PB with ULPB based on 100\% PLA cores. However, the dependencies of the models on circumstances are different,

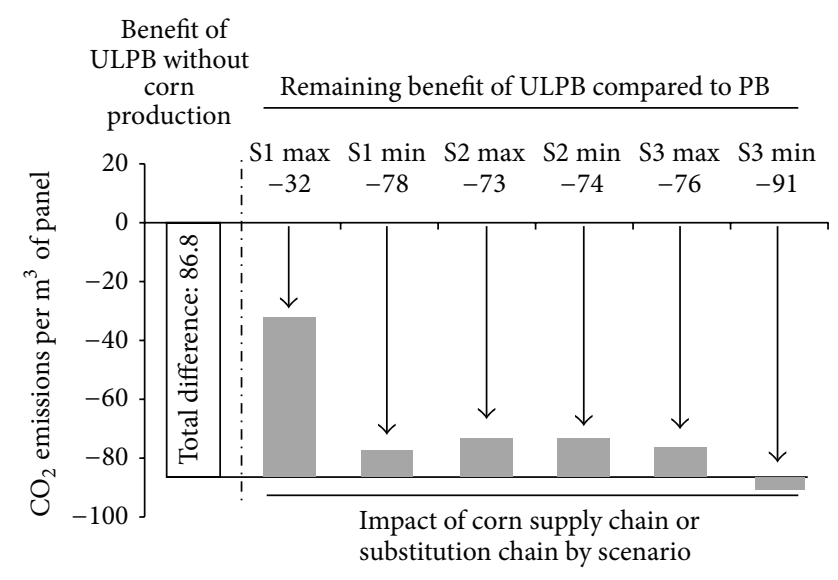

FIGURE 9: Results of scenarios used in the holistic approach.

and therefore recommendations to developers can be broadened by considering both models.

The differences between the panels observed with the EPD approach result from a reduction in the consumed electrical energy for the processes and exchanging UF with core material.

The holistic approach, on the other hand, takes more effects into account than the two described above. First of all, the amount of biomass which has to be burned to dry the extra amount of chips in the $\mathrm{PB}$ is recognized as not available for other applications. In contrast, the EPD approach only recognizes them in terms of their supply chain (in the case of recovered wood, only the transport is taken into account), since the carbon within the biomass is considered carbon neutral. This also means that reducing the amount of energy from biomass needed for the process has a much greater effect in the holistic approach than in the EPD approach.

Secondly, the characteristics of the recovered wood at the end-of-life are not taken into account in the EPD approach, but are in the holistic approach. Since the holistic approach assumes that the byproducts from sawmills are used elsewhere if not used within the panel, the model theoretically takes into account whether the incineration process of the pure sawmill byproducts would have been different from the process of burning the panels at their end-of-life. As we assumed these processes to be the same, no difference can be derived here, but in cases where the panels are burned at their end-of-life less efficiently due to mixed waste fractions, this would be taken into account by the holistic model.

Further on, the holistic model takes into account that PLA has to be produced from corn, which is a limited resource. If other routes for the corn exist, where the environmental benefit is higher than it is in the core layer of the ULPB, this is recognized by the holistic model. The EPD model does not take this into account.

With regard to the differences between PB and ULPB with PLA, the maximum PMMA content in the core layer of PMMA/PLA panels can be determined. The maximum here is defined as the point where the PLA/PMMA mixture core panels have no benefits compared to a conventional PB. In the worst case (maximum land use change) only $20 \%$ (5 kg) 
of PMMA and in the best case (minimum biogas) $56 \%(14 \mathrm{~kg})$ of PMMA can be included in the core layer. In the other cases, $45 \%$ to $48 \%$ define the threshold.

4.2. USETox and Ecological Scarcity 2006. Although not analyzed specifically in the holistic model, some general aspects in addition to the results of the EPD approach can also be derived for USETox and Ecological Scarcity.

In case of the UBP indicator, the incineration of wood has a very high impact. As the holistic model assumes that the sawmill byproducts will be burned at some point in time anyway, no matter whether they are used in the panel or not, the importance of the incineration of wood of the different panels will diminish drastically.

The USETox indicator for the PLA core panels is driven by the pesticides used during production of corn. This is included in the holistic model as well, but only if the production of an extra amount of corn is taken into account (Scenario 1). If available corn is used (Scenarios 2 and 3), the use of pesticides has a much lower impact.

\section{Recommendations}

The following recommendation can be made for the developers of ULPB with foam cores:

(i) The biopolymers used as foam precursor should have low energy demand or/and use renewable energies for their production. If possible, the chosen biopolymer should be produced out of biomass issued from organic agriculture (no pesticides or fertilizer) or sustainable managed forests. Their production should not be based on sugar derived from primary resources like corn but from waste flows (sugar, starch, and celluloses) which are not used elsewhere or only in a very inefficient way. This would exclude the land use change scenario from the model and would also avoid concurrency with the production of food.

(ii) The amount of UF resin should be reduced or better substituted by a renewable resource-based adhesive or recycled polymer adhesive with low energy consumption or/and use of renewable energies for manufacturing.

(iii) If PMMA is still necessary for enhancing the foaming and the foam properties, the portion of PMMA should be reduced as much as possible. If possible, PMMA should be substituted by a recycled polymer or a biopolymer with the same properties.

(iv) The technology should be developed in order to maintain the same production capacity, and if possible, to increase it.

(v) Besides the fact that the ULPB is already very light, decreasing the density even more could contribute to a reduction of the environmental burdens.

(vi) Solution for reducing the energy consumption of the particle preparation processes as well as the finishing processes (mainly the sanding) should be elaborated. (vii) The materials should be separable at their end-of-life. The efficiency of the waste treatment for the mixed fractions like PB should be as close to the efficiency of the incineration of the pure sawmill byproducts or the end-of-life treatment of products made of them other than panels.

(viii) The panel should be recyclable or able to be reused at the end-of-life instead of being incinerated.

\section{Conclusions}

With the aim of developing a product with a better environmental profile with respect to greenhouse gas emissions, the comparison done in this study shows that exchanging $\mathrm{PB}$ with $100 \%$ PLA core ULPB is beneficial. Exchanging conventional PB with ULPB based on EPS or PMMA/PLA cores is beneficial as well. However, the benefits of reducing the amount of adhesives in the ULPB compared to PB is almost made up for by the production of the foam core material if based on fossil resources. On the other hand, the use of conventional PLA induces specific agricultural issues mainly due to use of pesticides and fertilizers, land reconversion, land use, and agricultural process energy consumption.

This study shows that both EPD and holistic approaches were useful in order to forecast the environmental issues of in-development ultralight panels based on wood and biopolymers. Both approaches provided relevant recommendation for further development of these products.

\section{Conflict of Interests}

The authors declare that there is no conflict of interests regarding the publication of this paper.

\section{Acknowledgments}

The authors gratefully acknowledge the Swiss National Foundation Program NFP66 (Project 406640_136678) and the COST Action PF1303 of the EU RTD Framework Program for financial support of this study.

\section{References}

[1] A. May-Pat, F. Aviles, and J. Aguilar, "Mechanical properties of sandwich panels with perforated foam cores," Journal of Sandwich Structures and Materials, vol. 13, no. 4, pp. 427-444, 2011.

[2] L. J. Gibson and M. F. Ashby, Cellular Solids: Structure and Properties, Cambridge University Press, Cambridge, UK, 2nd edition, 1997.

[3] D. Zenkert, Handbook of Sandwich Construction, Engineering Materials Advisory Services, Worcester, UK, 2008.

[4] J. Luedtke, J. Welling, H. Thoemen, and M. C. Barbu, "Lightweight wood-based board and process for producing it," WO 2008/071617 A2, 2008.

[5] M. F. N. Dos Santos, R. A. G. Battistelle, B. S. Bezerra, and H. S. A. Varum, "Comparative study of the life cycle assessment of particleboards made of residues from sugarcane bagasse 
(Saccharum spp.) and pine wood shavings (Pinus elliottii)," Journal of Cleaner Production, vol. 64, pp. 345-355, 2014.

[6] S. Rueter and S. Diederichs, Ökobilanz-Basisdaten für Bauprodukte aus Holz, Thünen Institut, Hamburg, Germany, 2012.

[7] J. B. Wilson, "Life-cycle inventory of particleboard in terms of resources, emissions, energy and carbon," Wood and Fiber Science, vol. 42, no. 1, pp. 90-106, 2010.

[8] F. Werner and K. Richter, "Wooden building products in comparative LCA," The International Journal of Life Cycle Assessment, vol. 12, no. 7, pp. 470-479, 2007.

[9] B. Rivela, A. Hospido, M. T. Moreira, and G. Feijoo, "Life cycle inventory of particleboard: a case study in the wood sector," International Journal of Life Cycle Assessment, vol. 11, no. 2, pp. 106-113, 2006.

[10] A. Frühwald, M. Scharai-Rad, and J. Hasch, Ökologische Bewertung von Holzwerkstoffen Schlußbericht März 2000 Ergänzt in den Bereichen Spanplattenrecycling und OSB-Bilanzen, Universität Hamburg, Hamburg, Germany, 2000.

[11] S. Feifel, A. Faul, and L. Schebek, "Vergleichende ökologische Analyse leichter Holzwerkstoffplatten mit unterschiedlichem Aufbau," Holztechnologie, vol. 52, pp. 22-27, 2011.

[12] S. Feifel, W.-R. Poganietz, and L. Schebek, "The utilization of light weight boards for reducing air emissions by the German wood industry-a perspective?" Environmental Sciences Europe, vol. 25, no. 1, article 5, 2013.

[13] D. A. L. Silva, F. A. R. Lahr, A. L. R. Pavan et al., "Do wood-based panels made with agro-industrial residues provide environmentally benign alternatives? An LCA case study of sugarcane bagasse addition to particle board manufacturing," The International Journal of Life Cycle Assessment, vol. 19, no. 10, pp. 1767-1778, 2014.

[14] R. J. Plevin, M. A. Delucchi, and F. Creutzig, "Using attributional life cycle assessment to estimate climate-change mitigation benefits misleads policy makers," Journal of Industrial Ecology, vol. 18, no. 1, pp. 73-83, 2014.

[15] S. Suh and Y. Yang, "On the uncanny capabilities of consequential LCA," The International Journal of Life Cycle Assessment, vol. 19, no. 6, pp. 1179-1184, 2014.

[16] M. Brandão, R. Clift, A. Cowie, and S. Greenhalgh, “The use of life cycle assessment in the support of robust (climate) policy making: comment on "Using attributional life cycle assessment to estimate climate-change mitigation ...'”' Journal of Industrial Ecology, vol. 18, no. 3, pp. 461-463, 2014.

[17] J. M. Earles and A. Halog, "Consequential life cycle assessment: a review," The International Journal of Life Cycle Assessment, vol. 16, no. 5, pp. 445-453, 2011.

[18] EN 15804:2013. Sustainability of construction works. Environmental product declarations. Core rules for the product category of construction products; German version EN 15804:2012+A12013. Brussels: European Committee for Standardization, CEN/TC 350-Sustainability of con- struction works, 2013.

[19] ISO, "Environmental management-life cycle assessmentrequirements and guidelines," ISO 14044:2006, 2006.

[20] ISO 14025:2006, Environmental Labels and Declarations-Type III Environmental Declarations-Principles and Procedures, vol. 3, 2006.

[21] ISO, DIN EN ISO 14040:2006. Umweltmanagement-Ökobilanz-Grundsätze und Rahmenbedingungen, ISO, 2006.
[22] British Standards, "Round and sawn timber-environmental product declarations-product category rules for wood and wood-based products for use in construction," BS EN 16485: 2014, 2014.

[23] Aveny GmbH, Aveny LCA, 2012.

[24] R. Frischknecht, N. Jungbluth, H.-J. Althaus et al., "The ecoinvent database: overview and methodological framework," International Journal of Life Cycle Assessment, vol. 10, no. 1, pp. 3-9, 2005.

[25] A. Shalbafan, J. Luedtke, J. Welling, and H. Thoemen, "Comparison of foam core materials in innovative lightweight woodbased panels," European Journal of Wood and Wood Products, vol. 70, no. 1-3, pp. 287-292, 2012.

[26] H. Thoemen, "Ultra-light bio-based particleboard with a foam core-NRP 66 'Resource Wood"' 2012, http://www.nfp66 .ch/E/projects/wood-material-for-components/ultra-light-biobased-particleboard/Pages/default.aspx.

[27] BSI, "Particleboards-specifications," Tech. Rep. EN 312:2010, British Standards Institution, 2010.

[28] S. K. Diederichs, "2010 Status quo for life-cycle inventory and environmental impact assessment of the core sawmill products in germany," Wood and Fiber Science, vol. 46, no. 1, pp. 65-84, 2014.

[29] EN 15804: Sustainability of construction works-Environmental product declarations-Core rules for the product category of construction products, 2014.

[30] B. Weidema, "Market information in life cycle assessment," Environmental Project 863, Danish Environmental Protection Agency, 2003.

[31] T. Searchinger, R. Heimlich, R. A. Houghton et al., "Use of U.S. croplands for biofuels increases greenhouse gases through emissions from land-use change," Science, vol. 319, no. 5867, pp. 1238-1240, 2008.

[32] PE International, Gabi 4 Software and Gabi Professional Database, PE International, Stuttgart, Germany, 2012.

[33] B. Wicke, P. Verweij, H. van Meijl, D. P. van Vuuren, and A. P. C. Faaij, "Indirect land use change: review of existing models and strategies for mitigation," Biofuels, vol. 3, no. 1, pp. 87-100, 2012.

[34] H. Shapouri, J. A. Duffield, and M. Wang, "The energy balance of corn ethanol: an update," Agricultural Economic Report 813, US Department of Agriculture, Office of the Chief Economist, Office of Energy Policy and New Uses, 2002.

[35] R. Vogt, Basisdaten zu THG-Bilanzen für Biogas-Prozessketten und Erstellung neuer THG-Bilanzen, Insitut für Energie und Umweltforschung, Heidelberg, Germany, 2008.

[36] J. B. Guinée, R. Heijungs, G. Huppes et al., Life Cycle Assessment: An Operational Guide to the ISO Standards, Leiden University, Leiden, The Netherlands, 2001.

[37] R. Frischknecht, R. Steiner, and N. Jungbluth, The Ecological Scarcity Method-Eco-Factors 2006. A Method for Impact Assessment in LCA, Federal Office for the Environment (FOEN), Geneva, Switzerland, 2009.

[38] A. D. Henderson, M. Z. Hauschild, D. van de Meent et al., "USEtox fate and ecotoxicity factors for comparative assessment of toxic emissions in life cycle analysis: sensitivity to key chemical properties," The International Journal of Life Cycle Assessment, vol. 16, no. 8, pp. 701-709, 2011. 
[39] D. Laborde, "Assessing the land use change consequences of European biofuel policies," Specific Contract SI2.580403, International Food Policy Research Institute, 2011.

[40] I. Boustead, Eco-Profiles of the European Plastics IndustryPolymethyl Methacrylate (PMMA), PlasticsEurope, Brussels, Belgium, 2005.

[41] J. Lüdtke, Entwicklung und Evaluierung eines Konzepts für die kontinuierliche Herstellung von Leichtbauplatten mit polymerbasiertem Kern und Holzwerkstoffdecklagen, Hamburg University, 2011. 

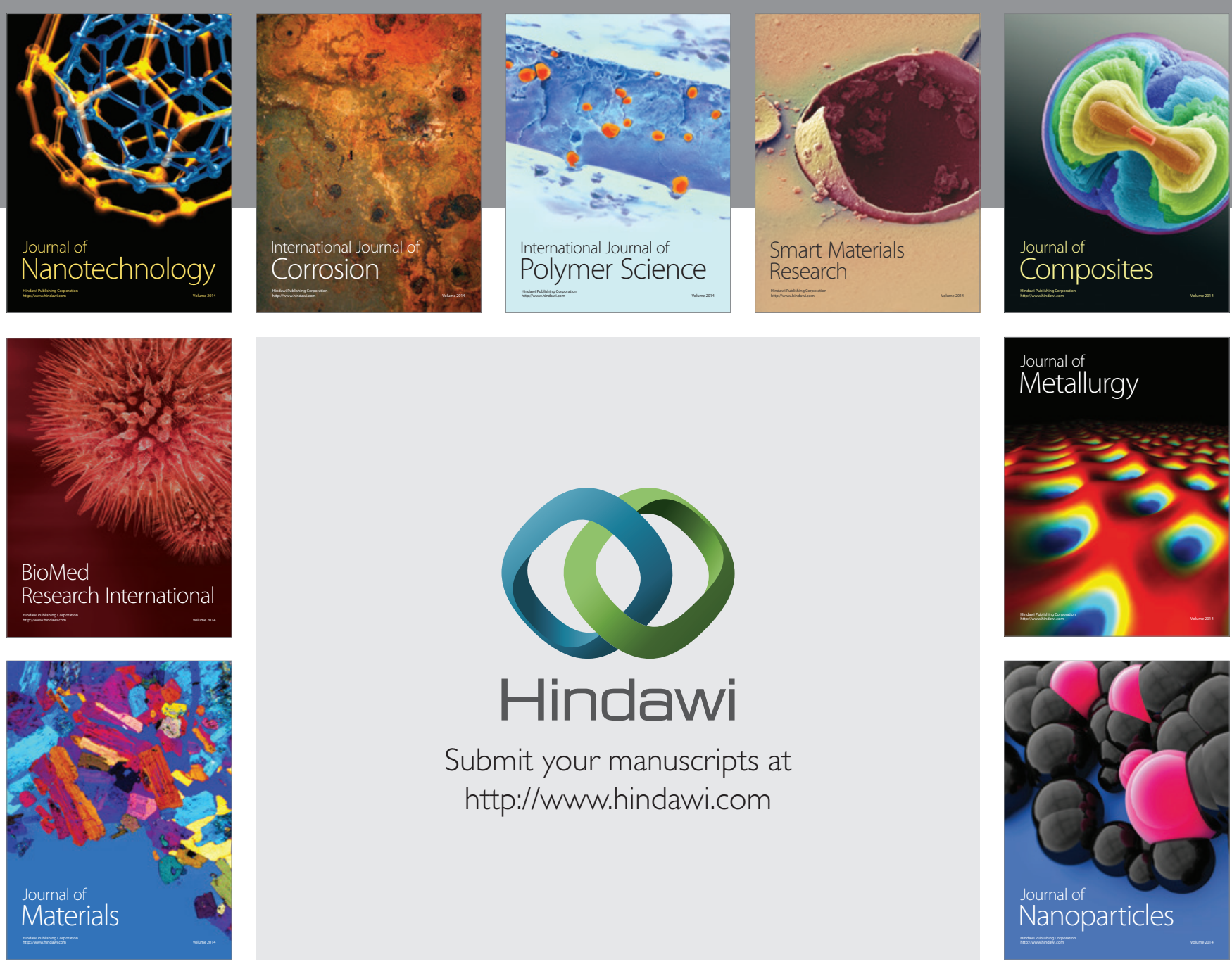

Submit your manuscripts at http://www.hindawi.com
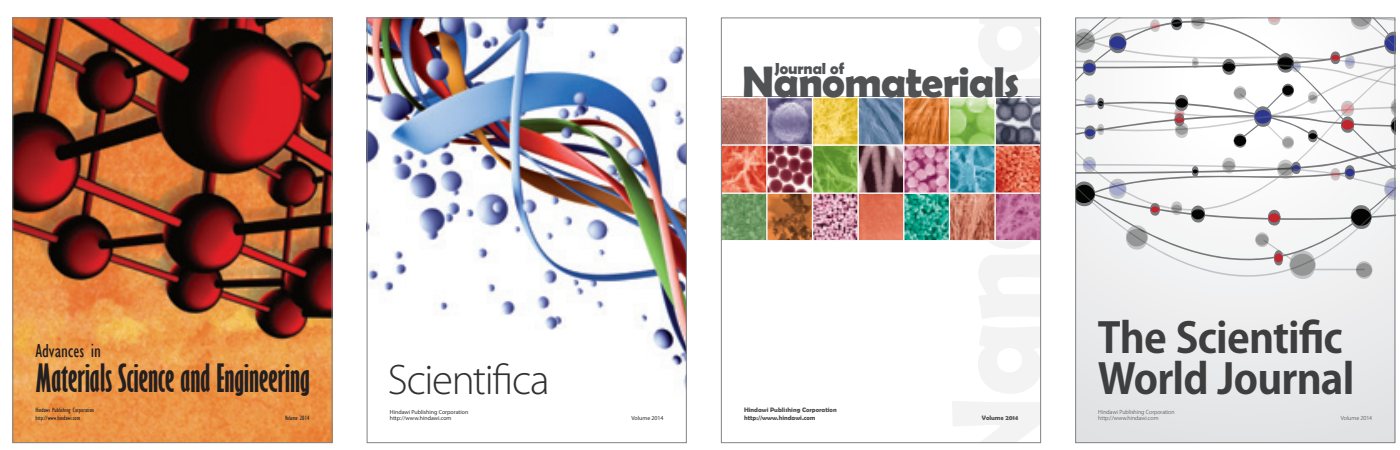

\section{The Scientific World Journal}
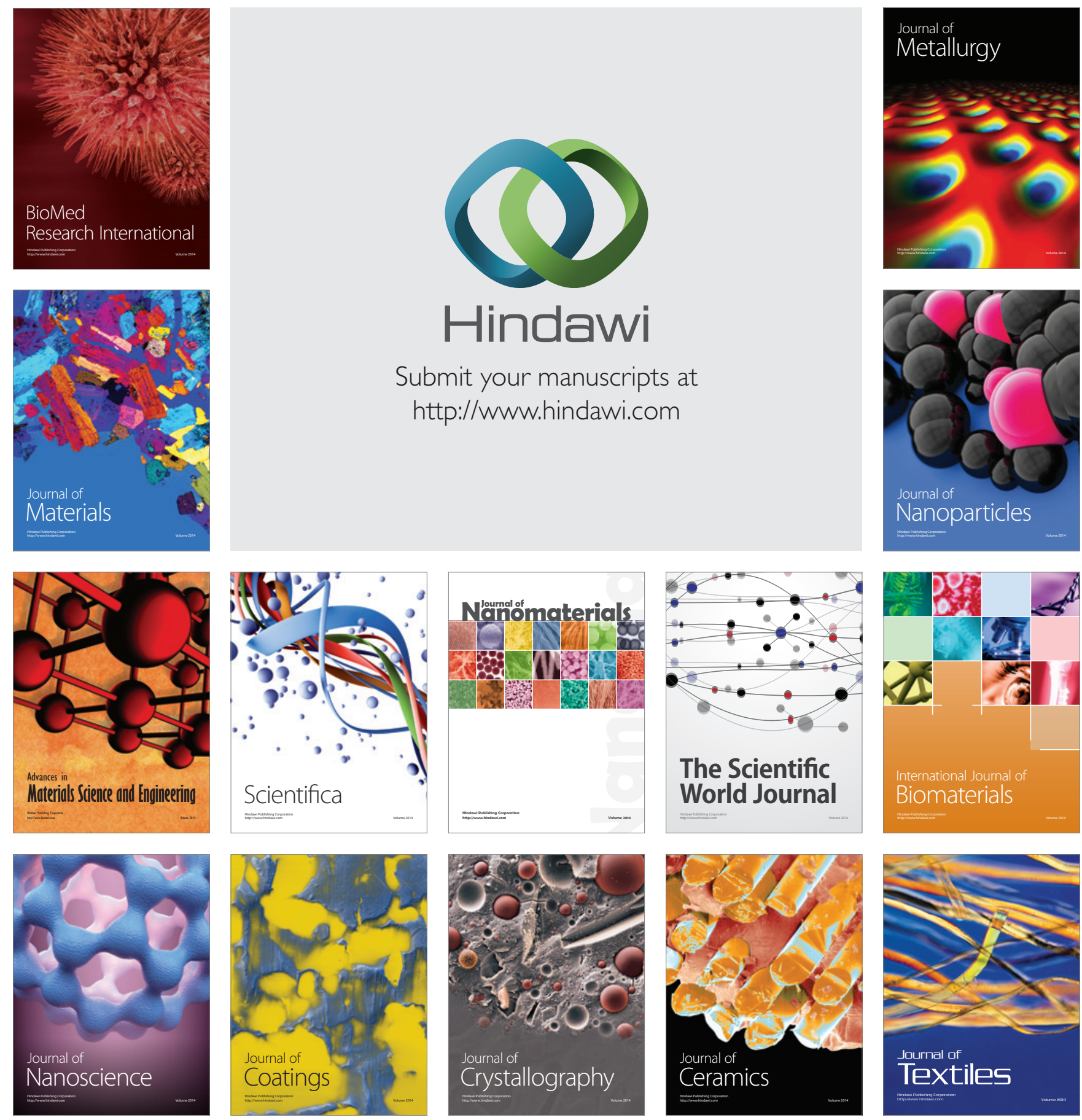